\title{
A Study on Mechanical Behaviour of Hybrid Reinforced Composite
}

\author{
P.Vignesh $^{1}$, M.Sengottaiyan ${ }^{2}$ \\ ${ }^{I}$ (PG Scholar, Department of Mechanical Engineering, Nandha Engineering College, Erode.) \\ ${ }_{2}^{2}$ (Assistant Professor, Department of Mechanical Engineering, Nandha Engineering College, Erode.)
}

\begin{abstract}
Over the last thirty years composite materials, plastics \& ceramics have been the dominant emerging materials. The volume \& number of applications of composite materials have grown steadily, penetrating and conquering new markets relentlessly. The composites have already proven their worth as weight-saving materials. The increasing demand for using environmentally friendly materials leads to usage of natural fibres. The fibres are reinforcement with polymers have gained importance due to its better properties. Natural fibers are not only strong and light weight but also relatively very cmaterials cheap and these fibers improve the environment sustainability of the parts being constructed. The natural fibers do not cause allergic reactions or skin irritation and gives better insulation and it can be easily degradable.
\end{abstract}

Keywords: Pineapple leaf fiber, Avianfiber, Epoxy resin, Preparation, Mechanical properties

\section{Introduction:}

Growing environmental, social and economic awareness, the concept of sustainability and new environmental regulations encourage exploration of new organic materials compatible with the environment [2]. The most important advantages of using polymers are the ease of processing, productivity, and reduction in cost. In most of these applications, the properties of polymers are altered by using fillers and fibers to suit the high strength/high modulus requirements [3].

\section{Literature Survey:}

Zuzanaet al. ${ }^{1}$ have studied about the three types of natural cellulosic fibers and their properties. The fibers used are corn, sunflower and hop. The natural fibers were cut into pieces with length varying from 20 to $40 \mathrm{~mm}$ to allow better impregnation when producing the composite plates. $100 \mathrm{~g}$ of polyester resin and $5 \mathrm{~g}$ of hardener are used as a matrix material. Samples were subjected to standardized tests such as tensile impact tests. The result shows about that corn and hop gives more tensile strength than sunflower.

Suradiet al. ${ }^{2}$ in this research oil-palm biofiber have been used. In which it consists of more amount of lignin and hemicellulose for a good interfacial bonding the content of these things should be less. To attain this property chemical treatment has been carried over such as alkali treatment in various percentage $(10 \%$, $15 \% \& 20 \%)$. Tensile and flexural test has done. The results of treated and untreated fibers are compared. In that the treated fiber gives more strength than untreated one.

J.P.Joget al. ${ }^{3}$ have studied about the types of natural fiber, microstructure and chemicalcomposition. While the moisture content, thermal properties and biodegradation has been discussed. While the thermoplastic and thermoset plastics have viewed. In this thermoplastic have more advantage than thermoset plastic. Internal content of fibers such as 60-80\% Cellulose,5-20\% Lignin\&Nearly 20\% Moisture present in it.

Milanese et al. ${ }^{4}$ in this research natural cellulosic sisal fiber have been choose. Sisal fiber diameter of about 100-200um.Different types of composition of fiber been taken. Various condition of fiber such as wet, moderate and dry types have been used for testing. Tensile and thermal tests are conducted. While the results shows that the moderate type sisal fiber gives more strength than the others.

Altafet al. ${ }^{5}$ the selected raw material of the fiber for this project work was Green Coconut fiber and the matrix material was HDPE (High Density Poly-ethylene). Mechanical properties viz., Tensile strength (TS), Flexural strength (FS) and Impact strength (IS) of the Flexural strength of the composite material decreasing with increasing the fiber volume fraction (Vf).green coconut fiber reinforced HDPE composite material is greatly influenced by fiber length as well as fiber volume fraction tensile strength of the composite material increases with increase in fiber volume fraction (Vf) up to $40 \%$, then after decreases slightly.

Mishra et al. ${ }^{6}$ Successful fabrication of the bidirectional jute fiber reinforced epoxy composite has been done by the hand lay-up technique.Void content decreases with the increase in fiber loading. The hardness, tensile properties and impact strength of the jute-epoxy composites increases with the increase in fiber loading. Reducing the void content will increase the properties. 
Sipiaoet al. ${ }^{7}$ in this research pineapple fiber have been used. Various types of testing methods have been discussed. Such as Scanning electron microscopy (SEM), X-ray diffraction (XRD) \&Thermal analysis (TGA).Chemical treatments are alkaline and distilled water has been used. The treated fibers are dried with the help of oven. Treated pineapple fiber has increased high impact strength of $14 \%$ than the untreated fiber.

Yuliatiet al. ${ }^{8}$ have studied about the different types of resins. Generally there are two types of resins such as low molecular weight (LM) PF resin type PL-3725 and high molecular weight (HM) PF resin type PL2818.Utilization of pineapple leaf fibre and PF resin is effective in prohibiting the degradation by termites. Pineapple leaf fibre MDF seems to be suitable for building construction materials. MDF specimens measuring $20 \times 15 \times 20 \mathrm{~mm}$ were obtained from MDF boards and exposed to the subterranean termites.

Isuwaet al. ${ }^{9}$ in this research Kenaf/PALF (Pineapple Leaf Fiber) Reinforced HDPE (High Density PolyEthylene) Composite have been studied. Tensile properties and water absorption behaviour discussed briefly.Modification was carried out on the fibre's surface using Vinyltri. Treated fiber has good results it absorbs less water than normal one. Therefore the treated fiber has more advantage than the normal one.

Nanthaya et al. ${ }^{10}$ have studied about the Fresh pineapple leaves, which contain about $85 \%$ water, are chopped into small pieces and ground into paste. Resin type used here arePolypropylene reinforcement.The PALF (Pineapple Leaf Fiber) the energy required to produce $2.27 \mathrm{MJ} / \mathrm{kg} .95 .4 \mathrm{MJ} / \mathrm{kg}$ and $100 \mathrm{MJ} / \mathrm{kg}$ are the energies required for the production of PP and glass fiber.

Nagarajaet al. ${ }^{11}$ have studied about the Rice straw and chicken feather. Here combinations of both natural and avian fiber have been combined together in various percentage. The hybrid composites. Show an increasing trend till $30 \%$ of fiber volume and then decreases for $40 \%$ and again it increases. Untreated fibres are used due to this action chemical treatments have been avoided. The orientations of fiber are randomly placed. Due to random orientation the strength of the fiber has been increased.

Sakthivelet al. ${ }^{12}$ in this researches both natural fiber and glass fibers have been used. Natural fiber used here are the banana. Hand lay-up method has been used for the manufacturing of plates. Glass fiber dust is so voluminous that it cannot be re-used as glass making material without treatment. Chemical treatment Noah will increases the flexural strength of the fiber up to $20-30 \%$ and removes the moisture content of the fiber. Regarding the glass fiber dust as an important resource for glassmaking the company decided to recycle it.

Chikkolet al. ${ }^{13}$ in this research properties of fiber reinforced composites had been enhanced through fiber surface modification. Alkali treated fiber have good mechanical properties than the untreated one. Lignocellulose fibers offer several advantages over their synthetic fibers. Experimental method has been proved to be the most effective method than any other. Diameter of the fiber will also affect the strength of the specimen.

Abilashet al. ${ }^{14}$ have studied about the E-glass which has been taken from the waste in the glass manufacturing industry. If Crack propagates a liquid healing agent comes out and fills the crack gap. BIOMIMETICS automatically heal when they are damaged. Healing time, healing efficiency, healing material. Natural cum synthetic fiber-reinforced polymer matrix composite has been discussed. Blended fiber reinforced polymer matrix composites shows better result as like virgin composite by its self-healing property.

Daudet al. ${ }^{15}$ in this research pineapple fiber has been studied. It contains of cellulose, holocellulose, hemicellulose and lignin with some extractive agents like resin and gum. $1 \%$ of sodium hydroxide has been treated with the fiber. Scanning Electron Microscope (SEM) analysis shows that the condensed arrangements of fibers which form a strong fiber structure than in any other fiber.

Fahimet al. ${ }^{16}$ in this research Low density polyethylene (LDPE) resin has been used. While the chemical treatments such as (phosphoric acid, sulphuric acid and sodium hydroxide). Phosphoric acid with $1 \%$ chemical concentration due to obtaining the highest values of tensile and flexural stress. Increasing the fiber concentration to $6 \%$ in the experi-mentation stage lowered the flexural stress 2 times and the tensile stress 4 times. Increasing the fiber length to $4 \mathrm{~mm}$ and $6 \mathrm{~mm}$ length reflected lower flexural and tensile stresses.

Fahimet al. ${ }^{17}$ in this research Plastic wastes are major environmental concern they are used as combination with fibres.RLDPE (Recycled Low Density Polyethylene) are discussed. Fiber and plastic wastes are treated with $1 \%$ of phosphoric acid. While the treated fiber shows the result of increases tensile strength of about 9 times.

\section{Conclusion:}

From the literature survey, selections of fibre materials are selected such as PALF (Pineapple Leaf Fibre) and avian. Resin type has been chosen as epoxy E-5013 with Heraldihyde. Preparation method has been the hand lay-up method. Testing methods has also been selected.

The above paper concludes that the combination of two fiber result more strength. Alkali treatment is necessary to improve property, thus thermoplastic has more benefits than others.Various condition wet, moderate and dry three modules been viewed. Tensile strength increases with addition of fiber. Void content will decrease the strength of specimens.SEM, XRD, TGA testing methods are followed and different types of 
resin has been viewed. Energy required to produce natural fiber is lesser than synthetic one. Finally through mixing of plant and animal fiber we can attain the good mechanical behavior of the specimen.

\section{References:}

[1]. ZuzanaJAMRICHOVÁ, Eva AKOVÁ. Mechanical testing of natural fiber composites for automotive industry.University Review, Vol. 7, 2013, No. 3, p. 20-25.

[2]. S.S.Suradi,R.M.Yunus,M.D.H.Beg,M.Rivai,Z.A.M.Yusof.Oil palm bio-fiber reinforced thermoplastic composites-effects of matrix modification on mechanical and thermal properties.Journal of applied science 10(24):3271-3276,2010.

[3]. D. NABI SAHEB and J. P. JOG. Natural Fiber Polymer Composites: A Review. Advancement in Polymer Technology 18: 351$363,2000$.

[4]. AndressaCecília Milanese, Maria OdilaHilárioCioffi and Herman JacobusCornelis Voorwald.Mechanical behavior of natural fiber composites.Procedia Engineering 10 (2011) 2022-2027.

[5]. Syed AltafHussain*,V.Pandurangadu,K.Palanikuamr. Mechanical properties of green coconut fiber reinforced hdpe polymer composite.ISSN : 0975-5462 Vol. 3, No. 11 November 2011.7952.

[6]. Vivek Mishra*, SandhyaraniBiswas. Physical and mechanical properties of bi-directional jute fiber epoxy composites. Procedia Engineering 51 ( 2013 ) $561-566$.

[7]. Sipiao,B.L.S. ${ }^{\text {a }}$ Paiva,R.L.M. ${ }^{\text {a }}$;Goulart,S.A.S. ${ }^{a}$;Mulinari,D.R. ${ }^{a}$. Effect of chemical modification on mechanical behaviour of polypropylene reinforced pineapple crown fibers composites.Procedia Engineering 10(2011) 2028-2033.

[8]. YuliatiIndrayania*, Dina Setyawatia, Tsuyoshi Yoshimurab, Kenji Umemurab. Termite Resistance of Medium Density Fibreboard Produced from Renewable Biomass of Agricultural Fibre. Procedia Environmental Sciences 20 ( 2014 ) 767 - 771.

[9]. Isuwa Suleiman Aji1*, Edi Syam Zainudin2, SalitMoh'd Sapuan3, Abdan Khalina4, and Moh'DZaman Khairul5.Effect of Fibre/Matrix Modification on Tensile Properties and Water Absorption Behaviour of Hybridized Kenaf/PALF Reinforced HDPE Composite.Journal of engineering and technology.e-ISSN:2319-9873 p-ISSN:2347-2324.

[10]. NanthayaKengkhetkit, TaweechaiAmornsakchai. A new approach to "Greening" plastic composites using pineapple leaf waste for performance and cost effectiveness. Materials and Design 55 (2014) 292-299.

[11]. B. Nagaraja Ganesh and B. Rekha. A Comparative Study on Tensile Behaviour of Plant and Animal Fiber Reinforced Composites. International Journal of Innovation and Applied Studies,ISSN 2028-9324 Vol. 2 No. 4 Apr. 2013, pp. 645-648.

[12]. R.Sakthivel, D.Rajendran.Experimental Investigation and Analysis a Mechanical Properties of Hybrid Polymer Composite Plates. (IJETT) - Volume 9 Number 8 - Mar 2014. ISSN: 2231-5381.

[13]. SrinivasaChikkol,BasavarajuBennehalli,MowneshGaddeKenchappa and Patel GowdaRanganagowda.Flexural behaviour of areca fibers composites.Bio-resources 5(3),1846-1858.

[14]. N.AbilashAndM.Sivapragash.Assesment of self healing Property in hybrid fiber Polymeric composite. International Journal of Engineering Science and Technology (IJEST) ISSN : 0975-5462,Vol. 3 No. 7 July 2011, 5430.

[15]. ZawawiDaud,MohdZainuriMohdHatta,Angzzas Sari MohdKassim and AshuvilaMohdAripin.Analysis of the chemical compositions and fiber morphology of pineapple(Ananascomosus) leaves in malaysia.Journal of applied science 14(12):1355-1358,2014.ISSN $1812-5654$.

[16]. Irene S. Fahim, Salah M. Elhaggar, HatemElayat.Experimental Investigation of Natural Fiber Reinforced Polymers. Materials Sciences and Applications, 2012, 3, 59-66.

[17]. Irene S. Fahim, Salah M. Elhaggar.Reinforcement of Plastic Waste with Treated Natural Fibers. Natural Resources, 2012 , 3, 6-10. 